\title{
DIAGNOSTIC EVALUATION OF HEPATOPULMONARY SYNDROME IN EGYPTIAN CHILDREN WITH CHRONIC LIVER DISEASE
}

\author{
MOHIEE EL-DEEN ABD EL-AZIZ AWAD ${ }^{1 *}$, HANAA AHMED EL-ARABI ${ }^{2}$, KHALED \\ ABD ELSALAM EL-SHARNOUBY ${ }^{3}$, AND KHALED ABD ELWAHAB ABO DEWAN \\ Departments of Pediatrics ${ }^{1}$, Pediatric Hepatology ${ }^{2}$, Cardiology ${ }^{3}$ and Radiology ${ }^{4}$, \\ Faculty of Medicine, Tanta University ${ }^{1,3,4}$, and National Liver Institute, Menoufia \\ University², Egypt. (Correspondence*: mohyeldeenawad@gmail.com)
}

\begin{abstract}
There are few data on prevalence of hepatopulmonary syndrome (HPS) in children with chronic liver disease (CLD). This prospective study evaluated the prevalence and diagnostic procedures of HPS in Egyptian children with CLD. One hundred twenty (120) children with CLD were subjected to room-air pulse oximetry in supine and upright position, contrast enhanced echocardiography (CEE) and technetium-99m-labeled macroaggregated albumin $\left({ }^{99 \mathrm{~m}} \mathrm{Tc}-\mathrm{MAA}\right)$ perfusion lung scan. Arterial blood gas (ABG) analysis in upright position was performed for all children with identified intrapulmonary vascular dilatation (IPVD). Clinical, laboratory, imaging and endoscopic data were recorded and analyzed.

Results: Hypoxemia was found in 14 cases $(11.7 \%)$ of the total cohort all of them had IPVD, whereas 6 cases $(5 \%)$ of the patients had IPVD without hypoxemia. Therefore, HPS and subclinical HPS were diagnosed in $11.7 \%$ and $5 \%$ of CLD patients, respectively. Only $10 \mathrm{HPS}$ patients had a pathological arterial oxygen saturation $\left(\mathrm{SaO}_{2}\right)$ in the supine position $(\leq 97 \%)$ but all showed a pathological $\mathrm{SaO}_{2}$ decrease $(\geq 4 \%)$ after changing from supine to upright position. ${ }^{99 \mathrm{~m}} \mathrm{Tc}-\mathrm{MAA}$ perfusion lung scan revealed IPVD in $16.7 \%$ whereas CEE detected IPVD in $10 \%$ only of enrolled patients. There were strong correlations between shunt index estimated by lung scintiscan and oxygenation parameters in HPS patients. The characteristics of HPS patients were similar to that of non-HPS patients except for clubbing, dyspnea, cyanosis, orthodoexia and bleeding varices that were more associated with HPS patients as well as well as the Child-Pugh grades, which tended toward higher scores in HPS patients.
\end{abstract}

Key words: hepatopulmonary syndrome, chronic liver disease, children, pulse oximetry, contrast-enhanced echocardiography, technetium-99m-labeled macroaggregated albumin perfusion lung scan.

\section{Introduction}

Hepatopulmonary syndrome (HPS) is characterized by oxygenation abnormalities caused by intrapulmonary vascular dilatation (IPVD) in the setting of liver disease (Krowka and Cortese 1990; RodríguezRoisin et al. 2004). Because of the high morbidity and mortality of HPS, clinicians have been trying to understand the pathophysiology of IPVD in the hope that the process can be reversed pharmacologically or surgically (Mazzeo et al, 2004). The pathogenesis of HPS is not completely understood. An imbalance between production and clearance of vasoactive circulating substances such as nitric oxide, glucagon and endothelin-1 has been implicated in the pathogenesis of HPS by causing IPVD, particularly in the less well-ventilated dependent basal parts of the lungs (Ho, 2008; Khan et al, 2011; Grace et al, 2013). This IPVD is responsible for the three physiological mechanisms that contribute to impaired gas exchange in HPS: ventilation-perfusion mismatch, diffusion limitation, and shunting. Ventilation-perfusion (V/Q) mismatch appears to be the major event in the pathogenesis of hypoxemia in HPS as a result of extensive IPVD with over-perfusion and a de- 
crease in V/Q ratio in alveolar-capillary units with subsequent low partial pressure of oxygen $\left(\mathrm{PaO}_{2}\right)$ and $\mathrm{O}_{2}$ content of blood leaving the lungs (Rodríguez-Roisin et al, 2004; Khan et al, 2011; Grace et al, 2013). The special clinical manifestations of HPS are platypnea, defined as dyspnea induced by the upright position and relieved by recumbency and orthodeoxia, defined as arterial deoxygenation induced by the upright position and relieved by recumbency (Robin et $a l, 1976)$. The natural history of HPS is characterized by a progressive deterioration, which leads to severe dyspnea and a high mortality rate after 4-5 years from the beginning of the respiratory symptoms (Lange et al, 1995; Swanson et al, 2005). Recent reports have documented increased mortality in patients with HPS who are awaiting liver transplantation (LTx) (Rodríguez-Roisin et al, 2004; Grace et al, 2013). Although LTx seems feasible to reverse this situation and can result in reversal of IPVD with substantial or total improvement in postoperative gas exchange abnormalities, it is associated with increased postoperative morbidity and mortality in adults (Sotct et al, 1993; Wang et al, 2005) and children (Fewtrell et al, 1994; Barbé et al, 1995; Durand et al, 1998; Samyn et al, 2004).

Given that the only effective cure for HPS is LTx, identification of patients with HPS is clinically important (Przybyowski et al, 2006). The diagnosis of HPS in a patient with CLD is established by demonstration of hypoxemia or elevated alveolar-arterial oxygen gradient $\left(\mathrm{PA}-\mathrm{a} \mathrm{O}_{2}\right)$ on arterial blood gas (ABG) analysis and the presence of IPVD using contrast-enhanced echocardiography (CEE) or technetium-99m-labeled macroaggregated albumin $\left({ }^{99 \mathrm{~m}} \mathrm{Tc}-\mathrm{MAA}\right)$ perfusion lung scan (Krowka et al 1990; Krowka et al, 2000; Grace et al, 2013). It was reported that $\mathrm{CEE}$ is the preferred screening test whereas ${ }^{99 \mathrm{~m}}$ Tc-MAA perfusion lung scan can further specify the diagnosis of HPS and quantify the magnitude of shunting (RodríguezRoisin et al, 2004; Wang et al, 2005; Grace et al, 2013). Routine use of ABG analysis to screen children for HPS is problematic because of the invasive nature of this test; however, pulse oximetry is well accepted by children, and an arterial oxygen saturation $\left(\mathrm{SaO}_{2}\right)$ of $\leq 97 \%$ measured by pulse oximetry identifies hypoxemia proved by ABG analysis $(\mathrm{PaO} 2<70 \mathrm{mmHg})$ in adults with cirrhosis, with sensitivity of up to $100 \%$ and specificity of $\sim 65 \%$ (Abrams et al, 2002; Mazzeo et al, 2006; Arguedas et al 2007). Although pulse oximetry is not a perfect replacement for ABG analysis (because of the shape of the oxyhemoglobin dissociation curve), its use to screen for HPS in children would potentially identify all children who have cirrhosis and meet the hypoxemia diagnostic criterion for HPS and would significantly reduce the number of children who do not have HPS and might otherwise be subjected to more invasive tests (Rodríguez-Roisin et al. 2004; Noli et al, 2008). The prevalence of HPS in adults with cirrhosis is reported to range from 4\% to 29\%, (Krowka et al 1990; Gupta et al, 2001; Schenk et al, 2002; Martínez et al, 2001; Schenk et al 2003; Lima et al 2004) with few data on its prevalence in children with chronic liver disease (CLD) (Noli et al, 2008). Although the prevalence of CLD is high in Egyptian children, however, few studies have reported the prevalence of HPS in this cohort (El-Shabrawi et al, 2010).

This prospective study was done to evaluate the prevalence and diagnostic procedures of HPS in a group of Egyptian children with CLD. Clarification of these aspects may be of clinical importance in decision making as regard timely referral of HPS patients for LTx evaluation.

\section{Patients, Materials and Methods}

The study included 120 children with a prior diagnosis of biopsy-confirmed CLD of varying etiologies who were selected from those admitted to the Hepatology Unit of Pediatric Department, Tanta University Hospitals and Pediatric Department o Ntional Liver Institute, Menoufia University, be- 
tween March and December 2013. Their ages ranged from 2 to 16 years (mean, $8.98 \pm 4.28 \mathrm{yrs}$ ). They were 70 males and 50 females. Diagnosis of CLD was based on clinical assessment as well as biochemical, serological, ultrasonographic and histopathological investigations. Patients with any primary cardiopulmonary disease were excluded from this study. The study was approved by the Postgraduate Clinical Research and Ethics Committee of Faculty of Medicine, Tanta University. The aim and nature of the study were explained for each parent and an informed written consent was obtained from parents before inclusion.

Clinical, laboratory, imaging and endoscopic evaluation: Thorough history and clinical examination were performed with special emphasis on 'cardiopulmonary' findings including dyspnea, platypnea, cyanosis, and digital clubbing. All patients were tested for hepatitis B, hepatitis C, biliary, autoimmune, metabolic and cardiac etiologies. Stool analysis, complete blood count, liver function tests, serum creatinine, prothrombin time and other routine tests were measured in all patients. All patients were examined by abdominal ultrasonography for the assessment of liver, spleen and ascites. Upper gastrointestinal endoscopic examination was performed to assess the presence of esophageal varices and manage bleeding varices. Plain chest $\mathrm{x}$-ray, electrocardiogram and colored-Doppler echocardiography were done for all patients and those with cardiovascular and known respiratory diseases were excluded from this study.

Pulse oximetry: Measurement of $\mathrm{SaO}_{2}$ was performed with a portable pulse oximeter (Nihon Kohden Corporation, Japan) over 10 minutes. In all children, the measurements were performed with the child resting and breathing room air in supine position. A second reading was taken after 10 minutes in upright position. A pathological test result was defined as: (i) $\mathrm{SaO}_{2} \leq 97 \%$ in supine position as the pulse oximetry threshold for the identification of hypoxemia was considered $\leq 97 \%$ in several previous studies (Abrams et al, 2002; Arguedas et al, 2007). (ii) A decrease in $\mathrm{SaO}_{2}$ of $\geq 4 \%$ after change from supine to the upright position $\left(\Delta \mathrm{SaO}_{2}\right)$ (Whyte et al, 1998). Orthodeoxia was defined as a decrease in $\mathrm{SaO}_{2}$ by 6 or more percentage points or to a value $\leq 92 \%$ upon standing from a supine position (Whitworth et al, 2009).

Contrast-enhanced echocardiography (CEE): All children underwent transthoracic CEE to identify evidence of IPVD. CEE was performed by a single operator who was blinded to the clinical and oximetry data. After confirmation of normal cardiac anatomy, 10 $\mathrm{mL}$ of hand agitated normal saline solution was rapidly injected intravenously and echocardiographic images for one minute after injection were digitally recorded for analysis. This technique is based on the formation of microbubbles that are normally trapped and absorbed by the normal pulmonary capillaries during the first pass and therefore do not appear in the left heart (Hind et al, 1981). In the presence of intrapulmonary or intracardiac right-to-left-shunts, however, microbubbles will opacify the left heart. In case of intracardiac right-to-left shunts, microbubbles appear within three heart beats after the appearance in the right chambers. Patients with such finding were excluded from the study. In patients with intrapulmonary shunts microbubbles was in left heart after four to six heart beats (Hopkins et al, 1992).

Technetium-99m-labeled macroaggregated albumin $\left({ }^{99 \mathrm{~m}} \mathrm{Tc}-\mathrm{MAA}\right)$ perfusion lung scan was performed in all children to demonstrate IPVD. Albumin macroaggregates are larger than $20 \mu \mathrm{m}$ in diameter and are normally trapped in the pulmonary capillaries (diameter 8 to $15 \mu \mathrm{m}$ ). Uptake of radionuclide by kidney, brain etc., therefore, indicates pathological passage through intrapulmonary or intracardiac shunts. With the child in the upright position for $10 \mathrm{~min}, 0.05$ $\mathrm{mCi} / \mathrm{kg}{ }^{99 \mathrm{~m}} \mathrm{Tc}-\mathrm{MAA}$ was injected intravenously without specific preparation. After 20 
minutes, quantitative whole-body imaging including spot views for the chest, skull, and lumbar regions (kidneys) were performed in supine position using a large-field-of-view dual-head $\gamma$-camera fitted with all-purpose, low energy, high resolution hole collimator (General Electric, Infinia, USA). Computer aided calculation of whole body and pulmonary activity with a matrix of $256 \times 256$ was performed using regions of interest drawn over the lungs, brain, soft tissues and kidneys. The extrapulmonary shunt fraction, assuming that $13 \%$ of the cardiac output is delivered to the brain, was calculated using the geometric mean of technetium counts in the brain and lung as described by Abrams and others (Figure 1). Normally, less than $5 \%$ of the isotope can be quantitated over the brain. The shunt fraction was considered positive if the brain uptake value was $\geq 6 \%$ (Abrams et al, 1998; Krowka et al, 2000; Wolfe et al, 1977).

Arterial blood gas (ABG) analysis was performed by blood gas system (Gastat-602 $i$, Techno-Medica, Japan) for all children with positive CEE and or lung scan. With the child resting, sitting and breathing room air, an arterial blood sample was obtained from the radial artery to assess the $\mathrm{PaO}_{2}$ and the $P(\mathrm{~A}-\mathrm{a}) \mathrm{O}_{2}$ gradient. An abnormal $\mathrm{ABG}$ was defined as $\mathrm{PaO} 2<80 \mathrm{mmHg}$ or $P(\mathrm{~A}$ a)O2 gradient of $\geq 15 \mathrm{mmHg}$ (Schenk et al, 2002; Fallon et al, 2000). ABGs, CEE and perfusion lung scan were performed within 7 days of $\mathrm{SaO}_{2}$ measurements, and personnel performing and interpreting each of the studies were blinded to the results of the others.

Diagnosis of HPS was established when following criteria were fulfilled: (1) Arterial hypoxemia or oxygenation abnormalities detected by a $\mathrm{SaO}_{2} \leq 97$ or an arterial oxygen saturation difference $\left(\Delta \mathrm{SaO}_{2}\right)$ of $\geq 4 \%$ (Whyte et al, 1998; Abrams et al, 2002; Mazzeo et al, 2006; Deibert et al 2006; Arguedas et al 2007) and confirmed by $\mathrm{PaO}_{2}<80 \mathrm{mmHg}$ or an A-a gradient of $\geq 15$ mmHg (Schenk et al, 2002; Fallon et al, 2000). (2) Positive CEE and/or positive lung scintiscan according to the definition of the European Task Force (Rodríguez-Roisin et al. 2004). (3) Absence of any primary cardiopulmonary disease (Grace et al, 2013).The patients positive for the presence of hypoxemia and IPVD assessed by CEE and/or ${ }^{99 \mathrm{~m}}$ Tc-MAA, were diagnosed as classic HPS and those presenting with IPVD without hypoxemia were defined as subclinical HPS (Schenk et al, 2002).

Statistical Analysis: Descriptive data were expressed as frequency and percentage and quantitative data were given as $M e a n \pm S D$. Comparisons between 2 groups for normally distributed quantitative data were performed with a Student t-test. Qualitative data were analyzed by Chi-Square $\left(\mathrm{X}^{2}\right)$ test. Correlations were obtained by using Pearson correlation coefficient. $\mathrm{P}$ values of less than 0.05 were considered statistically significant.

\section{Results}

The etiology and presentation of CLD, demographic, clinical, laboratory and endoscopic data as well as the Child-Pugh grades of all enrolled children are given (Tab. 1).

Among 120 patients, 14 children (11.7\%) met the classic HPS criteria and 6 children (5\%) with IPVD without hypoxemia were defined as subclinical HPS. Specifically, 20 patients (16.7\%) had IPVD as evidenced by a positive CEE and/or lung scan. Of these 20 patients with IPVD, 14 subjects $(11.7 \%)$ had hypoxemia by supine $\mathrm{SaO} 2 \leq 97 \%$ and/or $\Delta \mathrm{SaO}_{2}$ of $\geq 4 \%$ and confirmed by $\mathrm{PaO}_{2}<80$ $\mathrm{mmHg}$ or $\mathrm{P}(\mathrm{A}-\mathrm{a}) \mathrm{O}_{2}$ gradient of $\geq 15 \mathrm{mmHg}$; thereby fulfilling criteria for the diagnosis of classic HPS. But, the additional 6 subjects with IPVD (5\%) had no hypoxemia as evidenced by supine $\mathrm{SaO}_{2}>97 \%$ and $\Delta \mathrm{SaO}_{2}$ of $<4 \%$ and confirmed by $\mathrm{PaO}_{2}>90 \mathrm{mmHg}$ and $P(\mathrm{~A}-\mathrm{a}) \mathrm{O}_{2}$ gradient of $<15 \mathrm{mmHg}$, thereby fulfilling criteria for the diagnosis of subclinical HPS. Of 14 patients with classic HPS, 10 children had $\mathrm{SaO}_{2} \leq 97 \%$ whereas the remaining 4 children had $\mathrm{SaO}_{2}>97 \%$ in supine position. Four with $\mathrm{SaO}_{2}>97 \%$ suffered hypoxemia as evidenced by a $\Delta \mathrm{SaO}_{2}$ 
of $\geq 4 \%$ and confirmed by $P(\mathrm{~A}-\mathrm{a}) \mathrm{O}_{2}$ gradient of $\geq 15 \mathrm{mmHg}$. The $\mathrm{PaO}_{2}$ of the 4 patients was between $80 \& 85 \mathrm{mmHg}$, whereas it was $<80$ but $\geq 60 \mathrm{mmHg}$ in 7 patients and $<60$ but $>50 \mathrm{mmHg}$ in 3 patients. Of the 20 patients with IPVD, ABG analysis confirmed the presence of hypoxemia in 14 children with HPS and excluded the presence of hypoxemia in the other 6 children with subclinical HPS. One hundred patients $(83.3 \%)$ had no IPVD as evidenced by a negative $\mathrm{CEE}$ and/or negative lung scan. All of these individuals, had $\Delta \mathrm{SaO}_{2}$ of $<4 \%$. Of these 100 patients without IPVD, only 6 subjects had isolated mild hypoxemia as evidenced by $\mathrm{SaO}_{2} \leq 97 \%$, whereas the other 94 children had $\mathrm{SaO}_{2}>97 \%$ in supine position. No confirmation by ABG analysis for the absence or presence of isolated hypoxemia was done for these patients as they had no IPVD. Contrast-enhanced echocardiography showed IPVD in 12 patients $(10 \%)$ only of the total cohort. Of these individuals; 10 subjects were classic HPS whereas the other 2 subjects were subclinical HPS. But, ${ }^{99 \mathrm{~m}}$ Tc-MAA lung scan revealed IPVD in 20 patients $(16.7 \%) ; 14$ of them were classic HPS whereas the other 6 subjects $(5 \%)$ were subclinical HPS. The shunt index was estimated to be between $7 \%$ and $30 \%$ (mean $17.9 \%$ ). There was agreement between positive results of CEE and perfusion lung scan for identification of IPVD in 12 patients (10 with HPS \& 2 with subclinical HPS) whereas there was disagreement between both procedures with negative CEE but positive ${ }^{99 \mathrm{~m}}$ Tc-MAA perfusion lung scan result in 8 cases ( 4 with HPS \& 4 with subclinical HPS) (Tabs. 2, 3; Fig. 2). As regard pulse oximetry data, pathological $\mathrm{SaO}_{2}(\leq 97 \%)$ in supine position and pathological $\mathrm{SaO}_{2}$ decrease $\left(\Delta \mathrm{SaO}_{2}\right.$ of $\left.\geq 4 \%\right)$ after changing from supine to upright position were more significantly associated with HPS patients as compared to those without HPS. Mean $\mathrm{SaO}_{2}$ levels in patients with HPS as compared to patients without HPS were significantly lower in supine $(93.00 \pm 4.26 \%$ vs. $98.29 \pm 0.80 \%$, $\mathrm{p}<0.001)$ and upright position $(84.64 \pm 6.13$ $\%$ vs. $97.82 \pm 0.81 \%, \mathrm{p}<0.001)$. Mean $\mathrm{SaO}_{2}$ difference in HPS patients was $8.14 \pm 1.96$ compared to non-HPS patients, who showed minimal change $0.39 \pm 0.49(\mathrm{p}<0.001)$. Only 10 HPS patients had a pathological $\mathrm{SaO}_{2}$ in the supine position $(\leq 97 \%)$ but all showed a pathological $\mathrm{SaO}_{2}$ decrease $\left(\Delta \mathrm{SaO}_{2}\right.$ of $\left.\geq 4 \%\right)$ after changing from supine to upright position. In non-HPS patients, supine $\mathrm{SaO}_{2}$ was normal $(>97 \%)$ in 100 children whereas it was abnormal $(\leq 97 \%)$ in $6(5.7 \%)$ patients only. Abnormal values of supine pulse oximetry in these children had returned to normal levels after successful control of large volume ascites detected in these cases. No pathological $\mathrm{SaO}_{2}$ decrease after changing from supine to upright position was detected in all non-HPS patients i.e. $\Delta \mathrm{SaO}_{2}$ was $<4 \%$ (Fig. 2). Etiology and duration of CLD, demographic, clinical and laboratory data were similar between HPS and non-HPS patients except for cardiopulmonary findings (clubbing, dyspnea, cyanosis, orthodoexia) and bleeding varices that were more associated with HPS patients as well as Child-Pugh grades, which tended toward higher scores in HPS patients (Tab. 4-8). Sensitivity of orthodeoxia and clubbing for diagnosis of HPS was $100 \%$ \& $71.4 \%$, respectively (Tabs. 3, 5). Chest radiographs showed no abnormalities, as increased interstitial markings, in either group of patients.

Correlation study: $\mathrm{PaO}_{2}$ values on $\mathrm{ABG}$ in HPS patients correlated very well with oxygenation parameters by pulse oximetry including $\mathrm{SaO}_{2}$ in supine $(\mathrm{r}=0.97)$ and upright position ( $\mathrm{r}=0.96)$ as well as with $\mathrm{SaO}_{2} \%$ difference ( $\mathrm{r}=0.97$ (Tab. 9; Fig. 3A). Shunt index in HPS patients correlated well with oxygenation parameters by pulse oximetry including $\mathrm{SaO}_{2}$ in supine $(\mathrm{r}=-0.98)$, upright position $(\mathrm{r}=-0.97)$ and with $\mathrm{SaO}_{2} \%$ difference ( $r=0.95$, Fig 3B). Shunt index in HPS patients correlated well with oxygenation parameters by $A B G$ including $\mathrm{PaO}_{2}$ values $(r=-0.97) \& P(\mathrm{~A}-\mathrm{a}) \mathrm{O} 2$ values $(\mathrm{r}=0.94)$ (Tab.10). 
Table 1: Characteristics of total cohort

\begin{tabular}{|c|c|}
\hline Characteristics & Total patients $(\mathrm{n}=120)$ \\
\hline \multicolumn{2}{|l|}{ Demographic data } \\
\hline Age, Range, mean+SD (yrs.) & $2-16(8.98 \pm 4.28)$ \\
\hline Sex male/ female $\mathrm{n}(\%)$ & $70 / 50(58.3 \% / 41.7 \%)$ \\
\hline \multicolumn{2}{|l|}{ Etiology of CLD } \\
\hline Wilson disease, $n(\%)$ & $14(11.7 \%)$ \\
\hline Chronic viral hepatitis, $n(\%)$ & $24(20 \%)$ \\
\hline Autoimmune hepatitis, $n(\%)$ & $30(25 \%)$ \\
\hline Cirrhotic biliary atresia, n (\%) & $30(25 \%)$ \\
\hline Congenital hepatic fibrosis, $\mathrm{n}(\%)$ & $11(9.15 \%)$ \\
\hline Bilharzial hepatic fibrosis, $\mathrm{n}(\%)$ & $11(9.15 \%)$ \\
\hline \multicolumn{2}{|l|}{ Presentations of CLD } \\
\hline Cirrhotic CLD, n (\%) & $78(65 \%)$ \\
\hline Chronic hepatitis, n (\%) & $20(16.7 \%)$ \\
\hline Non-cirrhotic hepatic fibrosis n (\%) & $22(18.3 \%)$ \\
\hline \multicolumn{2}{|l|}{ Clinical manifestations } \\
\hline Jaundice n (\%) & $120(100 \%)$ \\
\hline Ascites n (\%) & $62(58.5 \%)$ \\
\hline Spider nevi n (\%) & $67(63.2 \%)$ \\
\hline Clubbing $\mathrm{n}(\%)$ & $12(10 \%)$ \\
\hline Cyanosis n (\%) & $5(4.2 \%)$ \\
\hline Dyspnea n (\%) & $5(4.2 \%)$ \\
\hline Hepatomegaly n (\%) & $50(41.7 \%)$ \\
\hline Splenomegaly $\mathrm{n}(\%)$ & $120(100 \%)$ \\
\hline \multicolumn{2}{|l|}{ Laboratory data (range, mean+SD) } \\
\hline $\mathrm{Hb}(\mathrm{gm} / \mathrm{dl})$ & $(7-13) 10.33 \pm 1.45$ \\
\hline Platelets $\left(\times 10^{3} / \mathrm{ul}\right)$ & (45-150) 93.46 20.556 \\
\hline Serum ALT (IU/L) & $(20-210) 96.06 \pm 51.71$ \\
\hline Serum AST (IU/L) & $(18-280) 95.43 \pm 54.43$ \\
\hline Total serum bilirubin $(\mathrm{mg} / \mathrm{dl})$ & $(2-16) 5.29 \pm 3.50$ \\
\hline Total serum protein $(\mathrm{gm} / \mathrm{dl})$ & $(5.8-8.3) 7.08 \pm 0.51$ \\
\hline Serum albumin $(\mathrm{gm} / \mathrm{dl})$ & $(2.2-4) 2.97 \pm 0.25$ \\
\hline Prothrombin concentration (\%) & $(40-95) 67.83 \pm 12.32$ \\
\hline Child-Pugh grades, A/B/C n (\%) & $14 / 80 / 26(11.7 \% / 66.7 \% / 21.6 \%))$ \\
\hline Esophageal varices: Bleeding/ Non-bleeding, n (\%) & $40 / 40(33.3 \% / 33.3 \%)$ \\
\hline
\end{tabular}

ALT, alanine aminotransferase; AST, aspartate aminotransferase; Hb, hemoglobin; SD, standard deviation

Table 2: Positive result of CEE and ${ }^{99 \mathrm{~m}} \mathrm{Tc}-\mathrm{MAA}$ in HPS patients as compared to non-HPS patients

\begin{tabular}{|c|c|c|c|c|}
\hline Procedure & HPS patients $(n=14)$ & Non-HPS patients $(n=106)$ & $\mathrm{X}^{2}$ test & $p$-value \\
\hline Positive CEE.n (\%) & $10(71.4 \%)$ & $2(1.9 \%)$ & 58.949 & $<0.001^{*}$ \\
\hline Positive ${ }^{99 \mathrm{~m}}$ Tc-MAA, n (\%) & $14(100 \%)$ & $6(5.7 \%)$ & 72.598 & $<0.001^{*}$ \\
\hline
\end{tabular}

CEE, contrast enhanced echocardiography; ${ }^{99 \mathrm{~m}} \mathrm{Tc}-\mathrm{MAA}$, technetium-99m-labeled macroaggregated albumin; HPS, hepatopulmonary syndrome, ${ }^{*}$ Significant

Table 3: Pulse oximetry data in HPS patients as compared to non-HPS patients

\begin{tabular}{|c|c|c|c|c|}
\hline Pulse oximetry data & HPS patients $(n=14)$ & Non-HPS patients $(n=106)$ & $\mathrm{X}^{2}$ test or $\mathrm{t}$ - test & $\mathrm{p}$-value \\
\hline $\mathrm{SaO} 2$ sunine $\%$ & & & $\mathrm{X}^{2}$ test & \\
\hline$\leq 97 \%$ n $(\%)$ & $10(71.4 \%)$ & $6(5.7 \%)$ & \multirow{2}{*}{40.77} & \multirow{2}{*}{$<0.001 *$} \\
\hline$>97 \% \mathrm{n}(\%)$ & $4(28.6 \%)$ & $100(94.3 \%)$ & & \\
\hline $\mathrm{O}_{2}$ saturation difference $\%$ & & & & \\
\hline$\geq 4 \% \mathrm{n}(\%)$ & $14(100 \%)$ & $0(00 \%)$ & \multirow{2}{*}{110.493} & \multirow{2}{*}{$<0.001 *$} \\
\hline$<4 \%$ n $(\%)$ & $00(00 \%)$ & $106(100 \%)$ & & \\
\hline Orthodeoxia n (\%) & $14(100 \%)$ & $00(00 \%)$ & 110.493 & $<0.001^{*}$ \\
\hline B-Ouantitative data & & & $\mathrm{t}$ - test & $\mathrm{p}$-value \\
\hline $\mathrm{SaO} 2$ supine $\%$ & $93.00 \pm 4.26$ & $98.29 \pm 0.80$ & 11.60 & $<0.001^{*}$ \\
\hline $\mathrm{SaO} 2$ upright $\%$ & $84.64 \pm 6.13$ & $97.82 \pm 0.81$ & 21.30 & $<0.001^{*}$ \\
\hline $\mathrm{O}$, saturation difference $\%$ & $8.14 \pm 1.96$ & $0.39 \pm 0.49$ & -34.24 & $<0.001^{*}$ \\
\hline
\end{tabular}

$\mathrm{SaO}_{2}$, arterial oxygen saturation; $\Delta \mathrm{SaO}_{2}$, arterial oxygen saturation difference; HPS, hepatopulmonary syndrome; $\mathrm{SD}$, standard deviation, *Significant 


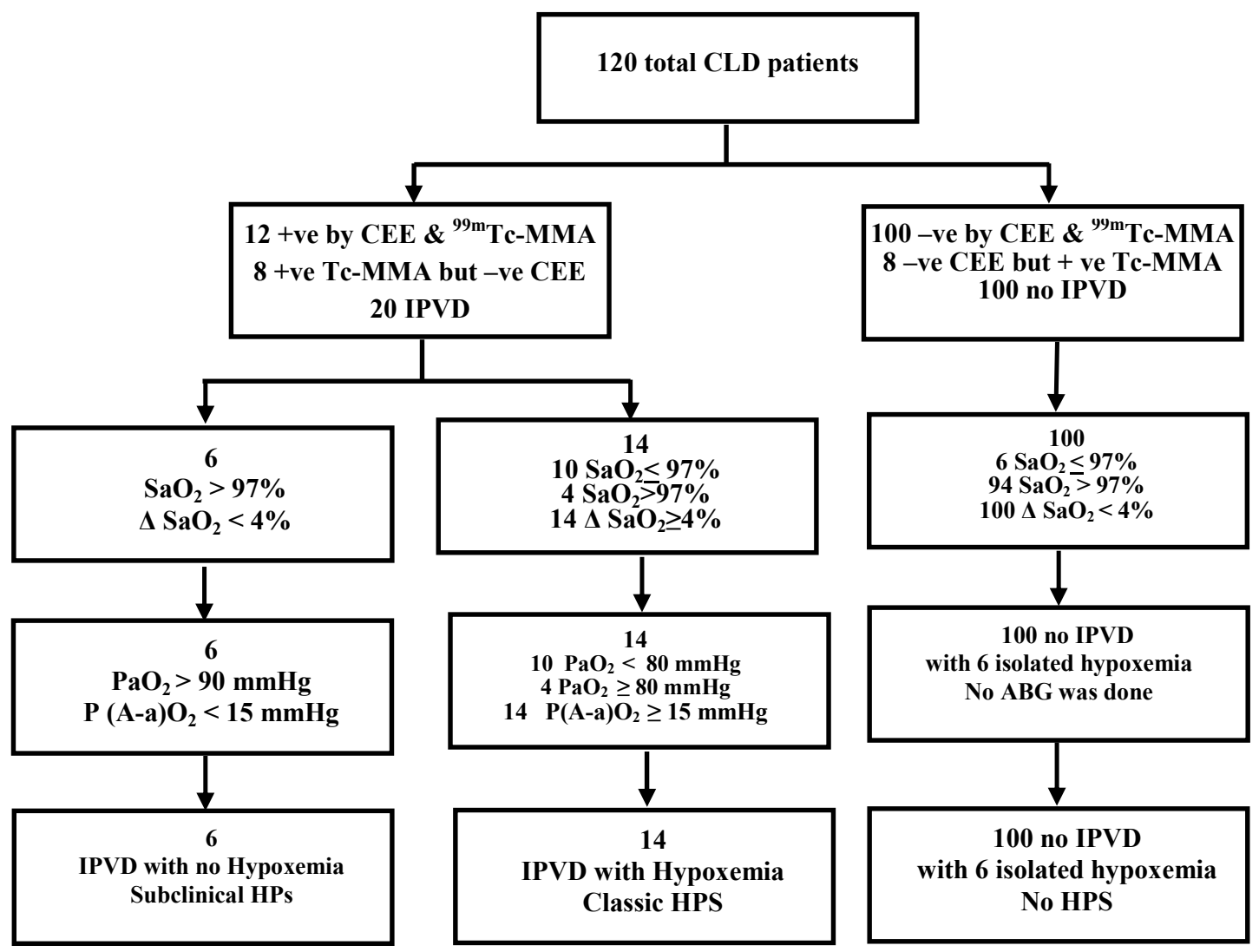

Fig. 2: Hepatopulmonary syndrome and intrapulmonary vascular dilatation evaluation

HPS, hepatopulmonary syndrome; IPVD, intrapulmonary vascular dilatation; CLD, chronic liver disease; ABG, arterial blood gas; CEE, contrast enhanced echocardiography; ${ }^{99 \mathrm{~m}} \mathrm{Tc}-\mathrm{MAA}$, technetium-99m-labeled macroaggregated albumin; $\mathrm{SaO}_{2}$, arterial oxygen saturation; $\Delta \mathrm{SaO}_{2}$, arterial oxygen saturation difference; $\mathrm{P}(\mathrm{A}-\mathrm{a}) \mathrm{O}_{2}$, alveolar-arterial oxygen gradient; $\mathrm{PaO}_{2}$, partial pressure of oxygen.

Table 4: Etiology, presentations and duration of CLD in HPS patients and non-HPS patients

\begin{tabular}{|c|c|c|c|c|}
\hline Data of CLD & HPS patients $(n=14)$ & Non-HPS patients $(n=106)$ & $X^{2}$ & $\mathrm{p}$-value \\
\hline Etiology of CLD & & & \multirow{6}{*}{2.067} & \multirow{6}{*}{0.723} \\
\hline Wilson disease, $n(\%)$ & $2(14.3 \%)$ & $12(11.3 \%)$ & & \\
\hline Chronic viral hepatitis, $n(\%)$ & $2(14.3 \%)$ & $22(20.8 \%)$ & & \\
\hline Autoimmune hepatitis, $n(\%)$ & $2(14.3 \%)$ & $28(26.4 \%)$ & & \\
\hline Cirrhotic biliary atresia. n (\%) & $4(28.6 \%)$ & $26(24.5 \%)$ & & \\
\hline Congenital hepatic fibrosis. $\mathrm{n}(\%)(\%)$ & $2(14.3 \%)$ & $9(8.5 \%)$ & & \\
\hline Bilharzial hepatic fibrosis. $\mathrm{n}(\%)(\%)$ & $2(14.3 \%)$ & $9(8.5 \%)$ & & \\
\hline \multicolumn{5}{|l|}{ Presentations of CLD } \\
\hline Cirrhotic CLD. n (\%) & $10(71.4 \%)$ & $68(64 \%)$ & \multirow{3}{*}{2.067} & \multirow{3}{*}{0.723} \\
\hline Chronic hepatitis, n (\%) & $0(00 \%)$ & $20(19 \%)$ & & \\
\hline Non-cirrhotic hepatic fibrosis. $\mathrm{n}(\%)$ & $4(28.6 \%)$ & $18(17 \%)$ & & \\
\hline Duration of CLD $\geq 3 \mathrm{yrs}, \mathrm{n}(\%)$ & $7(50 \%)$ & $60(56.6 \%)$ & 0.033 & 0.86 \\
\hline
\end{tabular}

CLD, chronic liver disease; HPS, hepatopulmonary syndrome

Table 5: Clinical manifestations in HPS patients and non-HPS patients

\begin{tabular}{|l|c|c|c|c|}
\hline Clinical manifestations & HPS patients $(\mathrm{n}=14)$ & Non-HPS patients $(\mathrm{n}=106)$ & $\mathrm{X}^{2}$ test & $\mathrm{p}$-value \\
\hline Clubbing $\mathrm{n}(\%)$ & $10(71.4 \%)$ & $2(1.9 \%)$ & 41.4 & $<0.001 *$ \\
\hline Cvanosis, $\mathrm{n}(\%)$ & $5(35.7 \%)$ & $00(00 \%)$ & 31.065 & $<0.001^{*}$ \\
\hline Dyspnea, $\mathrm{n}(\%)$ & $5(35.7 \%)$ & $00(00 \%)$ & 31.065 & $<0.001 *$ \\
\hline Jaundice. $\mathrm{n}(\%)$ & $14(100 \%)$ & $106(100 \%)$ & 0.00 & 1.00 \\
\hline Ascites. $\mathrm{n}(\%)$ & $8(57.1 \%)$ & $54(50.9 \%)$ & 0.023 & 0.87 \\
\hline Spider nevi. $\mathrm{n}(\%)$ & $7(50 \%)$ & $60(56.6 \%)$ & 0.033 & 0.86 \\
\hline Henatomegalv. $\mathrm{n}(\%)$ & $3(21.4 \%)$ & $47(44.3 \%)$ & 2.671 & 0.102 \\
\hline Solenomegalv. $\mathrm{n}(\%)$ & $14(100 \%)$ & $106(100 \%)$ & 0.00 & 1.00 \\
\hline
\end{tabular}


Table 6: Laboratory data in HPS patients and non-HPS patients

\begin{tabular}{|l|c|c|c|c|}
\hline Laboratory data (mean $\pm \mathrm{SD})$ & $\begin{array}{c}\text { HPS patients } \\
(\mathrm{n}=14)\end{array}$ & $\begin{array}{c}\text { Non-HPS patients } \\
(\mathrm{n}=106)\end{array}$ & t-test & $\begin{array}{c}\mathrm{p}- \\
\text { value }\end{array}$ \\
\hline $\mathrm{Hb}(\mathrm{gm} / \mathrm{dl})$ & $8.28 \pm 3.85$ & $9.07 \pm 4.34$ & -0.647 & 0.519 \\
\hline Platelets $\left(\mathrm{x} 10^{3} / \mathrm{ul}\right)$ & $72.00 \pm 28.2$ & $96.30 \pm 17.64$ & -3.147 & 0.007 \\
\hline Serum ALT (IU/L) & $100.93 \pm 21.3$ & $95.45 \pm 19.7$ & 0.296 & 0.772 \\
\hline Serum AST (IU/L) & $117.40 \pm 25.5$ & $92.59 \pm 17.5$ & 0.981 & 0.343 \\
\hline Total serum bilirubin $(\mathrm{mg} / \mathrm{dl})$ & $6.57 \pm 2.19$ & $5.13 \pm 1.21$ & 1.01 & 0.328 \\
\hline Total serum protein $(\mathrm{gm} / \mathrm{dl})$ & $7.16 \pm 0.33$ & $7.08 \pm 0.53$ & 0.605 & 0.546 \\
\hline Serum albumin $(\mathrm{gm} / \mathrm{dl})$ & $3.00 \pm 0.124$ & $2.97 \pm 0.264$ & 0.421 & 0.675 \\
\hline Prothrombin concentration & $74.07 \pm 11.19$ & $67.01 \pm 12.27$ & 2.043 & 0.043 \\
\hline
\end{tabular}

ALT, alanine aminotransferase; AST, aspartate aminotransferase; Hb, hemoglobin; HPS, hepatopulmonary syndrome; SD, standard deviation

Table 7: Child-Pugh grades in HPS patients and non-HPS patients

\begin{tabular}{|c|c|c|c|c|}
\hline Child-Pugh grades & $\begin{array}{l}\text { HPS patients } \\
\quad(n=14)\end{array}$ & $\begin{array}{c}\text { Non-HPS patients } \\
(\mathrm{n}=106)\end{array}$ & $\mathrm{X}^{2}$ test & p-value \\
\hline Child A n (\%) & $0(00 \%)$ & $14(13.2 \%)$ & \multirow{3}{*}{23.413} & \multirow{3}{*}{$<0.001^{*}$} \\
\hline Child B n (\%) & $4(28.6 \%)$ & $76(71.7 \%)$ & & \\
\hline Child C n (\%) & $10(71.4 \%)$ & $16(15.1 \%)$ & & \\
\hline
\end{tabular}

HPS, hepatopulmonary syndrome, ${ }^{*}$ Significant

Table 8: Esophageal varices in HPS patients and non-HPS patients

\begin{tabular}{|c|c|c|c|c|}
\hline Esophageal varices & $\begin{array}{l}\text { HPS patients } \\
(\mathrm{n}=14)\end{array}$ & $\begin{array}{c}\text { Non-HPS patients } \\
(n=106)\end{array}$ & $\mathrm{X}^{2}$ test & p-value \\
\hline Bleeding varices, $\mathrm{n}(\%)$ & $10(71.4 \%)$ & $30(28.4 \%)$ & \multirow{3}{*}{4.804} & \multirow{3}{*}{$0.028^{*}$} \\
\hline Non-bleeding varices. $n(\%)$ & $2(14.3 \%)$ & $38(35.8 \%)$ & & \\
\hline Absent varices, n (\%) & $2(14.3 \%)$ & $38(35.8 \%)$ & & \\
\hline
\end{tabular}

HPS, hepatopulmonary syndrome, ${ }^{*}$ Significant

Table 9: Correlation between $\mathrm{PaO}_{2}$ and pulse oximetry data in HPS patients

\begin{tabular}{|l|c|c|}
\hline Pulse oximetry data & \multicolumn{2}{|c|}{$\mathrm{PaO}_{2}$} \\
\cline { 2 - 3 } & $\mathrm{r}$ & p-value \\
\hline $\mathrm{SaO}_{2} \%$ supine & 0.978 & $<0.001^{*}$ \\
\hline $\mathrm{SaO}_{2} \%$ upright & 0.963 & $<0.001^{*}$ \\
\hline $\mathrm{SaO}_{2} \%$ difference & -0.971 & $<0.001^{*}$ \\
\hline
\end{tabular}

HPS, hepatopulmonary syndrome; $\mathrm{SaO}_{2}$, arterial oxygen saturation; $\mathrm{PaO}_{2}$, partial pressure of oxygen, *Significant

Table 10: Correlation between shunt index and oxygenation parameters in HPS patients

\begin{tabular}{|l|c|c|}
\hline \multirow{2}{*}{ Oxygenation parameters } & \multicolumn{2}{|c|}{ Shunt index } \\
\cline { 2 - 3 } & -0.989 & p-value \\
\hline $\mathrm{SaO}_{2} \%$ supine & -0.971 & $<0.001^{*}$ \\
\hline $\mathrm{SaO}_{2} \%$ upright & 0.956 & $<0.001^{*}$ \\
\hline $\mathrm{SaO}_{2} \%$ difference $\left(\triangle \mathrm{SaO}_{20}\right)$ & -0.974 & $<0.001^{*}$ \\
\hline $\mathrm{PaO}_{2} \mathrm{mmHg}$ & 0.949 & $<0.001^{*}$ \\
\hline $\mathrm{P}(\mathrm{A}-\mathrm{a}) \mathrm{O}_{2} \mathrm{mmHg}$ & & $<0.001^{*}$ \\
\hline
\end{tabular}

HPS, hepatopulmonary syndrome; $\mathrm{SaO}_{2}$, arterial oxygen saturation; $\Delta \mathrm{SaO}_{2}$, arterial oxygen saturation difference; $\mathrm{P}(\mathrm{A}-\mathrm{a}) \mathrm{O}_{2}$, alveolar-arterial oxygen gradient; $\mathrm{PaO}_{2}$, partial pressure of oxygen. *Significant

\section{Discussion}

The prevalence of HPS and subclinical HPS in patients with cirrhotic and noncirrhotic CLD or portal hypertension (PHT) is variable and depends on the definition and methods used to detect hypoxemia and IPVD (Gupta et al 2000; Schenk et al, 2002; Rodríguez-Roisin et al, 2004; Khan et al, 
2011; Grace et al, 2013). In the absence of a gold standard test, a combination of clinical criteria is used to make a diagnosis of HPS. Although it is clear from previous studies that the use of different diagnostic thresholds for these clinical criteria has a significant effect on the measured prevalence of HPS, consensus has now largely been reached for appropriate diagnostic criteria (Rodríguez-Roisin et al.2004) although there is concern that the diagnostic precision may be suboptimal (Mandell et al, 2006). Our intention was not to detect clinically relevant cases only, but also to determine the true prevalence of HPS including minor forms. In this prospective study using widely accepted diagnostic criteria, we found hypoxemia in $11.7 \%$ of the total cohort all of them had IPVD, whereas $5 \%$ of the patients had IPVD without hypoxemia (Fallon et al, 2000; Schenk et al, 2002; Rodríguez-Roisin et al. 2004; Abrams et al, 2002; Mazzeo et al, 2006; Arguedas et al 2007). Therefore, classic HPS and subclinical HPS were diagnosed in $11.7 \%$ and $5 \%$ of the patients, respectively. The estimated prevalence of $11.7 \%$ for HPS lies within range of $4 \%$ to $29 \%$ reported by previous studies on adults (Schenk et al 2002; Schenk et al 2003; Lima et al 2004) and children (El-Shabrawi et al, 2010; Arikan et al, 2005) in this field.

In the present work, the estimated prevalence of $11.7 \%$ for arterial hypoxemia is higher than that previously reported by Noli et al, (2008) who reported hypoxemia in $2.6 \%$ of their pediatric patients with $\mathrm{SaO}_{2}$ level $\leq 97 \%$. This difference could be due to modification in methodology where the present study used pulse oximetry in supine and upright position, but Noli et al. (2008) used pulse oximetry in upright position only and hypoxemia in some HPS patients may not be detected in upright position alone as was reported (Deibert et al, 2006) and agreed with this study. However, Arguedas et al (2007) demonstrated higher prevalence $(32 \%)$ of HPS by using pulse oximetry in upright position. The difference is attributed to differ- ent clinical situations in both studies with all adult patients in Arguedas's group were liver transplant candidates. Also, prevalence of hypoxemia in this work is lower than that reported by El-Shabrawi et al. (2010) who found arterial hypoxemia in $45 \%$ of their pediatric patients with $\mathrm{PaO}_{2}$ level less than $90 \mathrm{mmHg}$. This difference is obviously related to dissimilarity in methodology where El-Shabrawi et al. (2010) diagnosed hypoxemia depending on higher thresholds of $\mathrm{PaO}_{2}$ on $\mathrm{ABG}$ in all of their patients, but the present study used pulse oximetry. The possibility that we would have diagnosed additional subjects with HPS, had we measured $\mathrm{PaO}_{2}$ from $\mathrm{ABG}$ analysis in all of our patients is unlikely because $A B G$ analysis was done for all children with proved IPVD and detected no hypoxemia in the other $5 \%$ of cases with isolated IPVD.

By using higher pulse oximetry thresholds $\left(\mathrm{SaO}_{2} \leq 97 \%\right)$, it was possible to reliably identify HPS patients with less severe hypoxemia, albeit the need for ABG determinations in a greater proportion of screened cohort. Similar results were reported by Arguedas et al. (2007). Previous consideration for the utility of pulse oximetry to detect arterial hypoxemia found that a $\mathrm{SaO}_{2} \leq 94 \%$ as a screening tool would detect all HPS patients with a $\mathrm{PaO}_{2}<60 \mathrm{mmHg}$ who were found to be of sufficient severity to be eligible for increased priority for LTx (Abrams et al, 2002; Arguedas et al, 2007). Thus, $\mathrm{SaO}_{2}$ measurement provides a widely available and objective mean for screening for the presence and severity of hypoxemia in HPS. Patients with HPS should be considered for surveillance for worsening hypoxemia (Arguedas et al, 2007) because it has been found that severe hypoxemia $\left(\mathrm{PaO}_{2} \leq 50 \mathrm{mmHg}\right)$ is associated with increased mortality in affected patients with and without LTx (Rodríguez-Roisin et al. 2004; Khan et al, 2011; Arguedas et al, 2005). The significant robust correlation between oxygenation parameters by pulse oximetry and $\mathrm{PaO}_{2}$ values detected in this 
study in accordance with prior studies (Arguedas et al, 2007; Deibert et al, 2006) could suggest that serial $\mathrm{SaO}_{2}$ measurements by pulse oximetry are sufficiently sensitive tool for detecting worsening oxygenation and monitoring for progression of hypoxemia in HPS patients.

Moreover, this study detected that not all HPS patients had a pathological $\mathrm{SaO}_{2}$ in the supine position but all showed a significant $\mathrm{SaO}_{2}$ decrease after changing from supine to upright position. Similar findings were reported previously (Deibert et al, 2006). Therefore, the use of pulse oximetry in upright position only would miss the diagnosis of hypoxemia in a significant proportion of cases. Also, a pathological $\mathrm{SaO}_{2}$ decrease of $\geq 4 \%$ after changing from supine to upright position correlated negatively with $\mathrm{PaO}_{2}$ values. These results confirm that pathological position change in $\mathrm{SaO}_{2}$ is more important for detection of hypoxemia in HPS patients than $\mathrm{SaO}_{2}$ in supine or upright position only.

Although pulse oximetry has acceptable accuracy in the diagnosis of hypoxemia, it will not detect patients whose early oxygenation abnormality consists of a high A-a gradient but not a low arterial $\mathrm{PaO}_{2}$. Consequently, adult guidelines recommend screening at-risk groups using $\mathrm{ABG}$ analysis initially (Rodríguez-Roisin et al, 2004). However, ABG analysis is an invasive procedure and is associated with potential risks, limiting its utility as a screening tool. Therefore, it is expected that the majority of pediatric patients would not readily accept the arterial puncture required for this approach (Noli et al 2008) and ABG analysis in this study was reserved for children with IPVD. Moreover, using a $\mathrm{PaO} 2<80 \mathrm{mmHg}$ or $\mathrm{P}(\mathrm{A}$ a) $\mathrm{O}_{2}$ gradient of $\geq 15 \mathrm{mmHg}$ as a marker for hypoxemia on ABG (as suggested by Schenk et al, 2002 and Fallon et al, 2000) in children with IPVD would have correctly identified all HPS patients in this study. According to a proposed grading scale for severity of HPS on ABG (Rodríguez-Roisin et al. 2004), we could assume that we have identified 4 patients with mild HPS (IPVD, A-a gradient $\geq 15 \mathrm{mmHg}$ and $\mathrm{PaO}_{2} \geq 80$ $\mathrm{mmHg}$ ) and 7 patients with moderate HPS (IPVD, A-a gradient $\geq 15 \mathrm{mmHg}$ and $\mathrm{PaO}_{2} \geq 60$ but $<80 \mathrm{mmHg}$ ) as well as 3 patients with severe HPS (IPVD, A-a gradient $\geq 15 \mathrm{mmHg}$ and $\mathrm{PaO}_{2}<60$ but $>50 \mathrm{mmHg}$ ). It is important to categorize HPS patients according to disease severity as it will affect their follow-up, time of referral for LTx and prognosis. While periodic follow-up (at least once a year, with pulse oximetry and/or ABG levels if necessary) is recommended for patients with mild and moderate HPS, consideration of LTx is vital for those with severe HPS (Rodríguez-Roisin et al, 2004).

The contrast-enhanced echocardiography (CEE) detected IPVD in $10 \%$ only of the total cohort in this study. This prevalence is in line with that previously reported by ElShabrawi et al. (2010) who found IPVD by CEE in $7.5 \%$ of their cohort. But, this prevalence is less than that reported by Noli et al. (2008) who reported a $27 \%$ prevalence of IPVD by CEE. Also a similar higher prevalence of IPVD by CEE was reported by Deibert et al. (2006) and Whitworth et al. (2009). These differences may be related to lack of standardization of CEE interpretation between centers and the use of alternative contrast agents such as indocyanine green solution and a modified gelatin solution (Krowka et al, 1990; Schenk et al, 2002; Rodríguez-Roisin et al, 2004; Deibert et al, 2006).

Perfusion lung scan with ${ }^{99 \mathrm{~m}}$ Tc-MAA showed IPVD in $16.7 \%$ of our patients. This finding is similar to that previously reported by El-Shabrawi et al. (2010). Thus the lung scan is more sensitive in detection of IPVD compared with CEE where only $10 \%$ of patients were detected in this study. This is mostly because of the fact that lung scan can detect small shunts; whereas CEE can miss small shunts (Khan et al, 2011). Furthermore, the present study in accordance with prior studies (Abrams et al, 1998; Deibert et 
al 2006) showed that the shunt index estimated by lung scan correlated very well with oxygenation parameters in the HPS patients. This correlation may allow prediction of the severity of the shunt volume without performing lung scanning as suggested by Deibert et al (2006). These results are in agreement with many authors who reported that the low radiation hazard lung scan is a more sensitive, specific, accurate and rather simple test than CEE for detection and quantitative assessment of IPVD in the diagnosis of HPS in adults and children (Abrams et al, 1998; Aboussouan et al 2000; Deibert et al 2006; Khan et al, 2011; El-Shabrawi et al, 2010). But this technique by itself does not distinguish between intracardiac and intrapulmonary shunts (Wolfe et al, 1977; Khan et al, 2011). On the other hand, several authors had reported that CEE is more sensitive than lung scan (Abrams et al, 1995; RodríguezRoisin et al. 2004; Wang et al 2005; Grace et al, 2013). Moreover, CEE has additional advantages that it has no radiation exposure, it discriminate between intracardiac and intrapulmonary shunts and can be performed as a part of standard echocardiographic screening for pulmonary hypertension. For these reasons, some centers have adopted CEE as the first line screening modality for detection of IPVD in HPS (Grace et al, 2013). However, CEE is very much operator dependent, more labor intensive, lacks specificity and quantification of shunt is not possible. As to which imaging modality can be used depends on local availability both in terms of expertise and equipment (Khan et al, 2011).

In this study, subclinical HPS in $5 \%$ of children was comparable to that previously reported in adult (Anand et al, 2001; Schenk et al, 2002; 2003; Lima et al, 2004) and pediatric (Noli et al, 2008; Whitworth et al, 2009) studies in this field. In this study, if $\mathrm{CEE}$ and lung scan were performed only for those with pathological pulse oximetry as suggested previously by Deibert et al 2006, we would have missed the diagnosis of these
$5 \%$ of cases with subclinical HPS. Those particular patients with subclinical HPS may have dilated vessels large enough to allow passage of particles 20-50 microns in diameter to be detected by radionuclide lung scan and can still participate in gas exchange (Thoren et al, 1992). Small case series had showed that the abnormal CEE findings tend to persist and are therefore unlikely to represent false-positive scans (França et al, 2004; Langiulli et al, 2006). A retrospective study of 26 children with IPVD reported rapid progression (within 12 months) of hypoxemia in all ten children who had repeat $\mathrm{PaO}_{2}$ measurements and progression of IPVD in the 5 children who had repeat pulmonary scintiscans (Barbé et al, 1995). It remains unclear whether the progression of IPVD is dependent on the duration or the severity of CLD and PHT. The rate of progression of IPVD to HPS will need to be determined in prospective studies (Whitworth et al, 2009).

The present study found no significant differences in demographic or clinical features in patients with HPS compared with nonHPS patients, with the exception of clinical cardiopulmonary findings including clubbing, cyanosis, dyspnea, orthodeoxia, and oxygenation abnormalities on pulse oximetry that were more evident in association with the presence of HPS. This is concordant with other authors (El-Shabrawi et al, 2010; Mahmoodi et al, 2008). This could be explained by the fact that IPVD predominate in the lower lung fields in HPS patients and as gravity induces increased blood flow to these regions, hypoxemia is increased when changing from supine to upright position resulting in these clinical findings (Furukawa et al 1984; Sherlock 1988). It has been reported that although these phenomena are not pathognomonic for HPS, they strongly suggest this diagnosis in the setting of liver dysfunction (Arguedas et al 2005; Grace et al, 2013). However, other studies demonstrated that only oxygenation abnormalities by pulse oximetry showed significant differ- 
ences between HPS and non-HPS patients supporting the necessity of using pulse oximetry as an accurate and reliable mean for screening for hypoxemia in the diagnosis of HPS (Abrams et al, 2002; Mazzeo et al, 2006; Arguedas et al, 2007; Deibert et al, 2006). In this study, it was found that HPS insignificantly occurred across a spectrum of CLD etiologies and duration; but the presence of HPS was significantly associated with severity of CLD as assessed by the Child-Pugh score. This is in agreement with some pediatric (Arikan et al, 2005; Whitworth et al, 2009; El-Shabrawi et al, 2010) and adult (Hoeper et al, 2004) studies that reported an increased frequency of both IPVD and HPS in advanced CLD and a higher risk of HPS in Child $\mathrm{C}$ patients. Others reported that HPS was not more common in advanced CLD or PHT and did not correlate uniformly either with the severity or with the underlying cause of CLD or PHT (Krowka et al, 2000; Arguedas et al, 2007). The observation that HPS is not more common in advanced disease is a consistent finding in studies from the U.S., but this differs from several European centers (Vachiery et al, 1997; Schenk et al, 2003). The cause for this observation remains unclear but might reflect different geographic referral or screening patterns (Arguedas et al, 2007). Therefore, HPS should be considered in all patients with CLD or PHT regardless of its severity or etiology (Mahmoodi et al, 2008).

In this study, HPS was more associated with bleeding varices. This could be attributed to the advanced stages of hepatic dysfunction in cirrhotic patients. The ongoing cirrhotic process, with increasing PHT and opening of collaterals especially at the esophagogastric junction, are associated with more impairment of hepatocytic function resulting in failure of metabolism and/or production of vasoactive agents. These substances may reach the pulmonary vascular bed via portosystemic shunting, directly altering vessel tone causing IPVD with more evident hypoxemia in HPS (Hoeper et al,
2004). This is concordant with other authors who reported that HPS most commonly appears in CLD progressing to cirrhosis (E1Shabrawi et al, 2010; Khan et al, 2011; Grace et al, 2013). However, the occurrence of HPS in patients with chronic viral hepatitis without cirrhosis (Teuber et al, 2002) and in extrahepatic portal vein obstruction (Gupta et al, 2000) as well as in noncirrhotic portal fibrosis (Babbs et al, 1988; Deibert et al, 2006) suggests that that neither liver cirrhosis nor PHT is necessary for the development of the syndrome (Grace et al, 2013). In agreement with these data, we found HPS in $18.2 \%$ of children with noncirrhotic hepatic fibrosis. Screening for HPS and assessment of its severity has been recommended among patients who have cirrhosis and may be candidates for LTx (Rodríguez-Roisin et $a l, 2004)$. This recommendation arises from the influence that HPS has on the likelihood of survival both before and after LTx (Krowka et al, 2004; Samyn et al, 2004).

The results of the present study could support previous recommendation (Whitworth et al, 2009) that early recognition of HPS and monitoring progression of IPVD and hypoxemia may be important in the timing of LTx evaluation.

\section{Conclusions}

Classic HPS and subclinical HPS are relatively frequent in children with CLD. Orthodoexia and clubbing are the best clinical features in HPS patients.

The combined $\mathrm{SaO}_{2}$ determination in supine and upright position using pulse oximetery is a reliable, simple, low cost, and widely available technique for detection of hypoxemia in patients with HPS and should be performed during routine exams of children with CLD. ${ }^{99 \mathrm{~m}}$ Tc-MAA perfusion lung scan is more sensitive than CEE in the identification of IPVD in children with HPS or subclinical HPS. Further studies are needed to assess the progression of hypoxemia and IPVD in this cohort. 


\section{Acknowledgements}

The authors thank all of the participating children and their parents and Prof. Gamalat Mohamed Ali for performing statistical analysis of this study.

\section{References}

Aboussouan LS, Stoller JK, 2000: The hepatopulmonary syndrome. Baillieres Best Pract. Res. Clin. Gastroenterol. 14:1033-48.

Abrams, GA, Jaffe, CC, Hoffer, PB, Binder, HJ, Fallon, MB, 1995: Diagnostic utility of contrast echocardiography and lung perfusion scan in patients with hepatopulmonary syndrome. Gastroenterology 109: 1283-8.

Abrams, GA, Nanda, NC, Dubovsky, EV, Krowka, MJ, Fallon, MB, 1998: Use of macroaggregated albumin lung perfusion scan to diagnose hepatopulmonary syndrome: a new approach. Gastroenterology 114: 305-10.

Abrams, GA, Sanders, MK, Fallon, MB, 2002: Utility of pulse oximetry in the detection of arterial hypoxemia in liver transplant candidates. Liver Transpl. 8:391-6.

Anand, AC, Mukherjee, D, Rao, KS, Seth, AK, 2001: Hepatopulmonary syndrome: prevalence and clinical profile. Indian $\mathrm{J}$. Gastroenterol. 20:24-7.

Arguedas, MR, Fallon, MB, 2005: Hepatopulmonary syndrome. Curr. Treat. Options Gastroenterol. 8:451-6.

Arguedas, MR, Singh, H, Faulk, DK, Fallon, MB, 2007: Utility of pulse oximetry screening for hepatopulmonary syndrome. Clin. Gastroenterol. Hepatol. 5:749-54.

Arikan, C, Yuksekkaya, HA, Levent, E, et al, 2005: Childhood cirrhosis, hepatopulmonary syndrome and liver transplantation. J. Pediatr. Gastroenterol. Nutr. 40:673-8.

Babbs, C, Warnes, TW, Haboubi, NY, 1988: Non-cirrhotic portal hypertension with hypoxemia. Gut 29:129-31.

Barbé, T, Losay, J, Grimon, G, et al, 1995: Pulmonary arteriovenous shunting in children with liver disease. J. Pediatr. 126:571-9.

Deibert, P, Allgaier, HP, Loesch, S, Müller, C, Olschewski, M, et al, 2006: Heptaopulmonary syndrome in patients with chronic liver disease: role of pulse oximetry. BMC Gastroenterology 6:15.

Durand, P, Baujard, C, Grosse, AL, et al, 1998: Reversal of hypoxemia by inhaled nitric oxide in children with severe hepatopulmonary syndrome, type 1 , during and after liver transplantation. Transplantation 65:437-9.

El-Shabrawi, MH, Omran, S, Wageeh, S, Isa, M, Okasha, S, et al, 2010: $99 \mathrm{~m}$ Technetium-macroaggregated albumin perfusion lung scan versus contrast enhanced echocardiography in the diagnosis of the hepatopulmonary syndrome in children with chronic liver disease. Eur. J. Gastroenterol. Hepatol. 22: 1006-12.

Fallon, MB, Abrams, GA, 2000: Pulmonary dysfunction in chronic liver disease. Hepatology 32:859-65.

Fewtrell, MS, Noble-Jamieson, G, Revell, S, Valente, J, Friend, P, et al, 1994: Intrapulmonary shunting in the biliary atresia/ polysplenia syndrome: reversal after liver transplantation. Arch. Dis. Child. 70:501-4.

França, A, Lima, B, Pazin, FA, et al, 2004: Evolution of intrapulmonary vascular dilatations in cirrhosis. Hepatology 39:1454-9.

Furukawa, T, Hara, N, Yasumoto, K, Inokuchi, K, 1984: Arterial hypoxemia in patients with hepatic cirrhosis. Am. J. Med. Sci. 287:10-3.

Grace, JA, Angus, PW, 2013: Hepatopulmonary syndrome: update on recent advances in pathophysiology, investigation, and treatment. J. Gastroenterol. Hepatol. 28:2139.

Gupta, D, Vijaya, DR, Gupta, R, et al, 2001: Prevalence of hepatopulmonary syndrome in cirrhosis and extrahepatic portal venous obstruction. Am. J. Gastroenterol. 96: 3395-9. 
Gupta, NA, Abramowsky, C, Pillen, T, Redd, D, Fasola, C, et al, 2007: Pediatric hepatopulmonary syndrome is seen with polysplenia/interrupted inferior vena cava and without cirrhosis. Liver Transpl. 13: 680-6.

Hind, CR, Wong, CM, 1981: Detection of pulmonary arteriovenous fistulae in patients with cirrhosis by contrast 2D echocardiography. Gut 22:1042-5.

Ho, V, 2008: Current concepts in management of hepatopulmonary syndrome. Vasc. Hlth. Risk Manage 4:1035-41.

Hoeper, MM, Krowka, MJ, Strassburg, C P, 2004: Portopulmonary hypertension and hepatopulmonary syndrome. Lancet 363: 1461-8.

Hopkins, WE, Waggoner, AD, Barzilai, B, 1992: Frequency and significance of intraulmonary right-to-left shunting in end stage liver disease. Am. J. Cardiol. 70:516-9.

Khan, AN, Al-Jahdal, H, Abdullah, K et al, 2011: Pulmonary vascular complications of chronic liver disease: Pathophysiology, imaging, and treatment. Ann. Thoracic Med. 6:57-65.

Krowka, MJ, Cortese, DA, 1990: Hepatopulmonary syndrome. Chest 98:1053-4.

Krowka, MJ, Mandell, MS, Ramsay, MA, et al, 2004: Hepatopulmonary syndrome and portopulmonary hypertension: a report of the multicenter liver transplant database. Liver Transpl. 10:174-82.

Krowka, MJ, Tajik, AJ, Dickson, ER, Wiesner, RH, Cortese, DA, 1990: Intrapulmonary vascular dilatations (IPVD) in liver transplant candidates: screening by twodimensional contrast-enhanced echocardiography. Chest 97:116-70.

Krowka, MJ, Wiseman, GA, Burnett, OL, et al, 2000: Hepatopulmonary syndrome: a prospective study of relationships between severity of liver disease, $\mathrm{PaO}(2)$ response to $100 \%$ oxygen, and brain uptake after $(99 \mathrm{~m})$ Tc MAA lung scanning. Chest 118: 615-24.
Lange, PA, Stoller, JK, 1995: The hepatopulmonary syndrome. Ann. Int. Med. 122: 521-9.

Langiulli, M, Aronow, WS, Das, M, et al, 2006: Prevalence and prognosis of intrapulmonary shunts in patients with hepatic cirrhosis. Cardiol. Rev.14:53-4.

Lima, BL, Franca, AV, Pazin-Filho, A, et al, 2004: Frequency, clinical characteristics, and respiratory parameters of hepatopulmonary syndrome. Mayo Clin. Proc. 79:42-8.

Mahmoodi, E, Kianifar, HR, Partovi, S, Mafinejad, S, Bozorgnia, A, 2008: Intrapulmonary arteriovenous shunt in children with chronic liver disease: clinical features, laboratory outcome. Indian J. Gastroenterol. 27:16-8.

Mandell, MS, 2006: The diagnosis and treatment of hepatopulmonary syndrome. Clin. Liver Dis. 10:387-405.

Martínez, GP, Barbera, JA, Visa, J, et al, 2001: Hepatopulmonary syndrome in candidates for liver transplantation. J. Hepatol. 34:651-7.

Mazzeo, AT, Bottari, G, Pratico, C, Penna, O, Mandolfino, T, et al, 2006: Significance of hypoxemia screening in candidates for liver transplantation: our experience. Transplant. Proc. 38:793-4.

Mazzeo, AT, Lucanto, T, Santamaria, LB, 2004: Hepatopulmonary syndrome: a concern for the anesthetist? pre-operative evaluation of hypoxemic patients with liver disease. Acta Anesth. Scand. 48:178-6.

Noli K, Solomon M, Golding F, Charron M, Ling SC., 2008: Prevalence of hepatopulmonary syndrome in children. Pediatrics 121:e522-27.

Przybyowski, T, Krenke, R, Fangrat, A, Nasilowski, J, Grabczak, EM, Styczynskg, G, et al, 2006: Gas exchange abnormalities in patients listed for liver transplantation. J. Physiol. Pharmacol. 57:313-23.

Robin, ED, Laman, D, Horn, BR, Theodore, J, 1976: Platypnea related to ortho- 
deoxia caused by true vascular lung shunts. N. Engl. J. Med. 294:941-3.

Rodríguez-Roisin, R, Krowka, MJ, Herve, P, Fallon, MB, 2004: Pulmonary-hepatic vascular disorders (PHD). Eur. Respir. J. 24:861-80.

Samyn, M, Bourgois, A, Bansal, S, et al, 2004: Hepatopulmonary syndrome in children: a single centre experience. J. Pediatr. Gastroenterol. Nutr. 39, 1:S199.

Schenk, P, Fuhrmann, V, Madl, C, et al., 2002: Hepatopulmonary syndrome: prevalence and predictive value of various cut offs for arterial oxygenation and their clinical consequences. Gut 51:853-9.

Schenk, P, Schoniger-Hekele, M, Fuhrmann, V, Madl, C, Silberhumer, G, et al, 2003: Prognostic significance of the hepatopulmonary syndrome in patients with cirrhosis. Gastroenterology 125:1042-52.

Sherlock, S, 1988: The liver-lung interface. Semin. Resp. Med. 9:253-62.

Sotct, V, Miro, A, Kang, Y, DeWolf, A, Bellary, S, et al, 1993: Reversibility of the hepatopulmonary syndrome by orthotopic liver transplantation. Transplant. Proc. 25: 1787-8.

Swanson, KL, Wiesner, RH, Krowka, MJ, 2005: Natural history of hepatopulmonary syndrome: impact of liver transplantation. Heptaology 41:1122-9.
Teuber, G, Teupe, C, Dietrich, CF, Caspary, WF, Buhl, R, et al, 2002: Pulmonary dysfunction in non-cirrhotic patients with chronic viral hepatitis. Eur. J. Int. Med. 13: 311-8.

Thorens, E, Junod, AF, 1992: Hypoxaemia and liver cirrhosis: a new argument in favor of a 'diffuse perfusion defect'. Eur. Respir. J. 5:754-6.

Vachiery, F, Moreau, R, Hadengue, A, et al, 1997: Hypoxemia in patients with cirrhosis: relationship with liver failure and hemodynamic alterations. J. Hepatol. 27: 492-5.

Wang, YW, Lin, HC, 2005: Recent advances in hepatopulmonary syndrome. J. Chin. Med. Assoc. 68:500-5.

Whitworth, JR, Ivy, DD, Gralla, J, Narkewicz, MR, Sokol, RJ, 2009: Pulmonary vascular complications in asymptomatic children with portal hypertension. J. Pediatr. Gastroenterol. Nutr. 49: 607-12.

Whyte MK, Hughes, JM, Peters, AM, Ussov, W, Patel, S, Burroughs, AK, 1998: Analysis of intrapulmonary right to left shunt in the hepatopulmonary syndrome. J. Hepatol. 29:85-93.

Wolfe JD, Tashkin, DP, Holly, FE, Brachman, MB, Genovesi, MG, 1977: Hypoxemia of cirrhosis, detection of abnormal small pulmonary vascular channels by a quantitative radionuclide method. Am. J. Med. 63:746-54. 


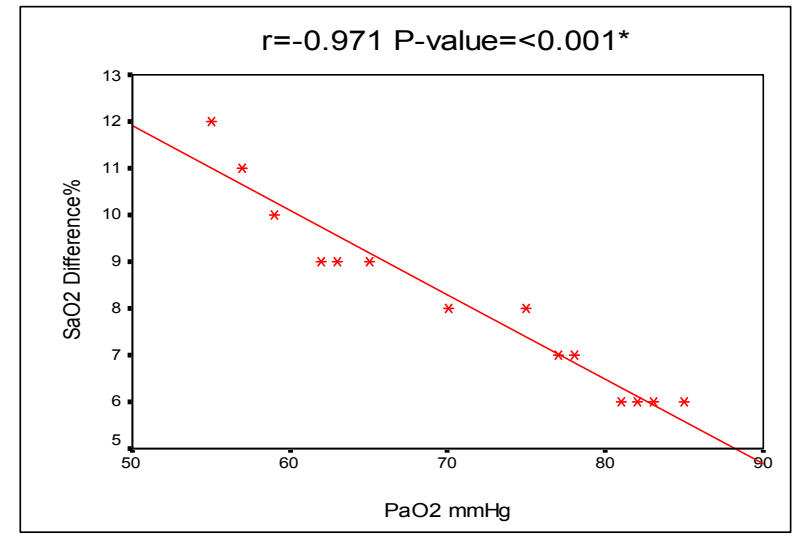

Fig 3 A

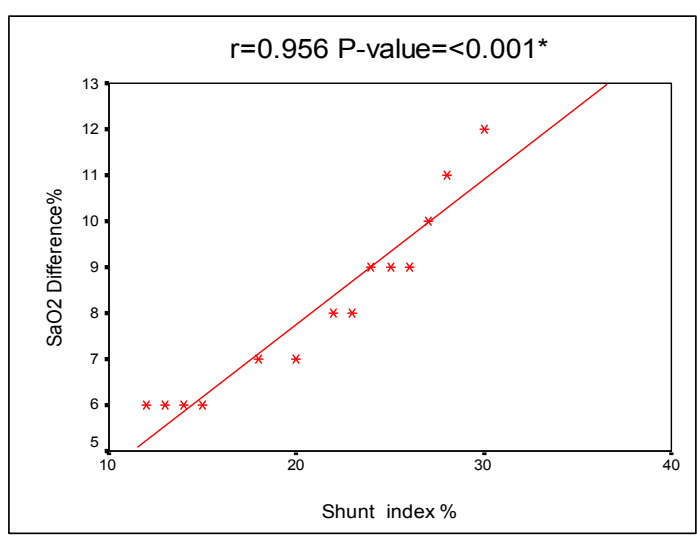

Fig 3 B

Fig. 3: Correlation between arterial oxygen saturation $\left(\mathrm{SaO}_{2} \%\right)$ difference and arterial partial pressure of oxygen $\left(\mathrm{PaO}_{2}\right)[\mathrm{A}]$ as well as shunt index $[\mathrm{B}]$ in patients with hepatopulmonary syndrome

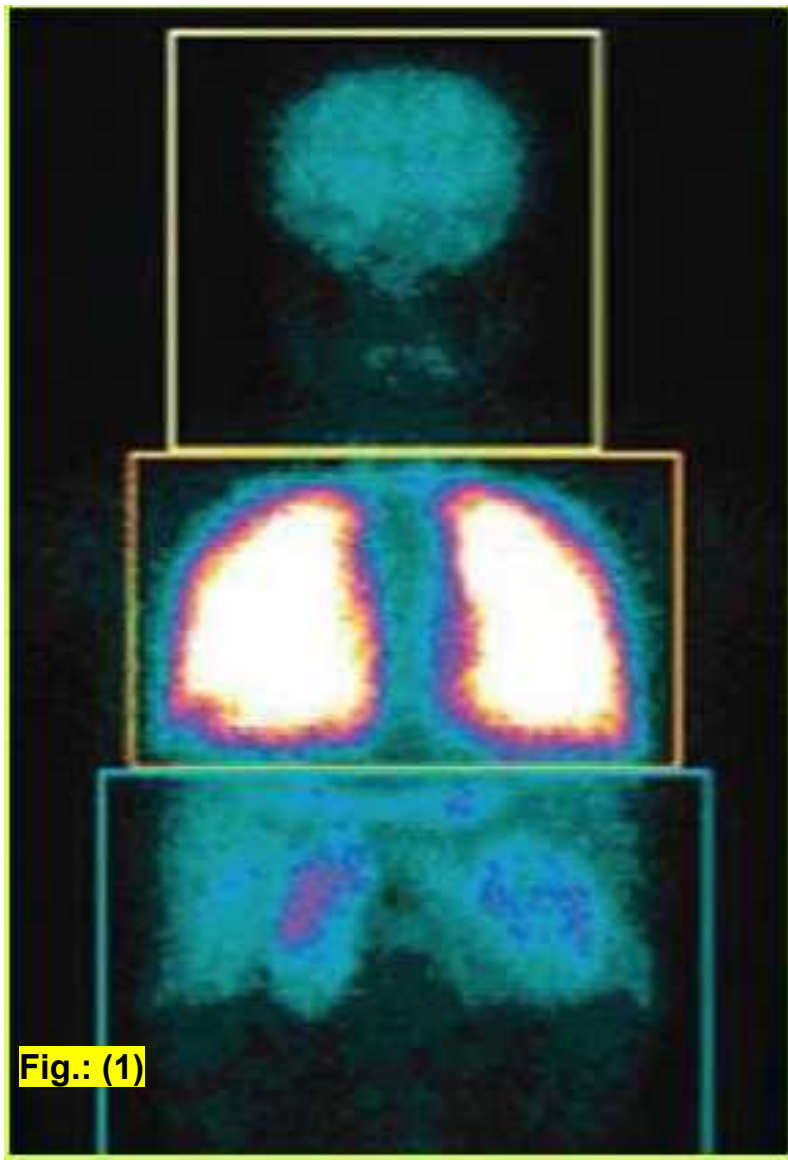

Fig.1: Technetium-99m-labeled macroaggregated albumin perfusion lung scan. Perfusion normal and symmetrical in both lungs, abnormal activity in brain and both kidneys indicating right to left shunt. To quantify right to left shunt, region of interests were drawn around brain and kidneys as well as around the lung.

$$
\text { I lepatopuinonary shunt }(\mathrm{H} \text { PS })=\frac{\frac{\text { GMIBC. (Brain) }}{0.13}}{\frac{\text { GMPC.(Brain) }}{0.13}+\text { GMICC(I.ung) }} \times 100
$$

Where GMBC $=$ Geometric mean brain count and GMLC $=$ Geometric mean lung count (Krowka et al, 2000). 